\title{
Aneurysmal and clinical characteristics as risk factors for intracerebral haematoma from aneurysmal rupture
}

\author{
Xiaomeng Liu • Gabriel J. E. Rinkel
}

Received: 10 September 2010/Revised: 17 November 2010/Accepted: 25 November 2010/Published online: 14 December 2010

(C) The Author(s) 2010. This article is published with open access at Springerlink.com

\begin{abstract}
Intracerebral haematoma (ICH) occurs in onethird of patients with aneurysmal subarachnoid haemorrhage $(\mathrm{SAH})$ and is associated with poor prognosis. Identification of risk factors for ICH from aneurysmal rupture may help in balancing risks of treatment of unruptured aneurysms. We assessed potential clinical and aneurysmal risk factors for $\mathrm{ICH}$ from aneurysmal rupture. In all $310 \mathrm{SAH}$ patients admitted to our service between 2005 and 2007, we compared clinical risk factors (gender, age, smoking, hypertension, history of SAH and family history) of patients with and without an ICH. From the latest admitted, 50 patients with and 50 without $\mathrm{ICH}$, we compared the location, shape and direction of blood flow of the aneurysms on CT-angiography. Relative risks (RRs) of ICH were 1.2 (95\% confidence interval, CI):0.7-1.8) for males, 1.0 (95\%CI:0.7-1.4) for age $\geq 55$ year, 1.0 (95\%CI:0.6-1.6) for smoking, 0.9 (95\% CI:0.5-1.5) for hypertension, 0.6 (95\% CI:0.1-3.8) for history of SAH and 0.5 (95\%CI:0.2-1.3) for family history of SAH. RRs of ICH were 1.8 (95\%CI:1.2-2.5) for MCA aneurysms, 0.5 (95\%CI:0.3-1.0) for ICA aneurysms, 0.4 (95\% CI:0.1-1.3) for posterior circulation aneurysms, and 0.7 (95\%CI:0.3-1.3) for multilobed aneurysms. The RRs of other aneurysmal characteristics varied between 0.9 and 1.2. Patients with MCA aneurysms are at a higher risk of developing ICH. The other aneurysmal or clinical factors have no or only minor influence on the risk of ICH after rupture and are, therefore, not helpful in deciding on treatment of unruptured aneurysms.
\end{abstract}

\footnotetext{
X. Liu · G. J. E. Rinkel ( $\square)$

Department of Neurology, Rudolf Magnus Institute of Neuroscience, University Medical Centre Utrecht, Room G03.228, P.O. Box 85500, 3508 GA Utrecht, The Netherlands

e-mail: G.J.E.Rinkel@umcutrecht.nl
}

Keywords Cerebrovascular disease - Clinical neurology · Subarachnoid haemorrhage - Intracerebral haematoma . CT-angiography $\cdot$ Risk factors

\section{Background}

In about one-third of patients with an aneurysmal subarachnoid haemorrhage (SAH) the haemorrhage extends into the parenchyma [1]. Patients with an intracerebral haematoma (ICH) after aneurysmal rupture have, in general, a worse clinical condition, higher fatality rate and smaller chance of functional recovery [2]. Risk factors for intraparenchymal extension are largely unknown. Previous studies found no influence of age, pre-existing hypertension or sex [2]. If risk factors can be identified, these factors could be included in the risk balance of treating unruptured aneurysms. In addition to clinical characteristics, aneurysm characteristics such as location, shape and direction of blood flow may contribute to the risk of ICH development.

We aimed to identify risk factors for intraparenchymal extension by comparing clinical and aneurysm characteristics between patients with and without intraparenchymal extension in a large cohort of patients with SAH.

\section{Methods}

From a prospectively collected database of patients admitted with SAH to our service, we retrieved all 310 patients who were admitted from January 2005 through December 2007 and who fulfilled the inclusion criteria for the current study: (1) patient's age was 18 years or higher at the time of diagnosis; (2) confirmed diagnosis of 
aneurysmal SAH by CT-scan and CT-angiography; and (3) the initial CT-scan was performed within $72 \mathrm{~h}$ from the onset of clinical symptoms. Patients with a clinical episode suggestive of rebleeding between admission and the initial CT-scan were excluded, as were patients with CT-angiography of poor quality or patients with multiple aneurysms in which the site of the ruptured aneurysm was unknown.

The following clinical information was retrieved for all patients from the database: (1) age; (2) gender; (3) smoking status, with smoking defined as a current smoker or quit smoking less than 10 years ago; (4) history of hypertension as diagnosed by physicians or the use of antihypertensive $\operatorname{drug}(\mathrm{s}) ;(5)$ history of SAH defined as a previous episode of $\mathrm{SAH}$, with treatment of the ruptured aneurysm; and (6) family history of $\mathrm{SAH}$, with positive family history defined as at least one first-degree relative with SAH.

We reviewed the admission CT-scans of these patients to determine the presence of $\mathrm{ICH}$ independent from the clinical information. ICH was defined as an intraparenchymal blood collection with a diameter $\geq 1 \mathrm{~cm}$ on plain CT-scan. Then we sorted the patients by the time of diagnosis and retrieved the CT-angiograms of the latest 50 consecutive patients with and the latest 50 consecutive patients without an ICH. In these 100 patients, we assessed location and shape of the aneurysm and direction of blood flow into the aneurysm. With 50 patients per category, we had sufficient power to detect a risk ratio of 1.8 for risk factors present in half of the study population. We considered smaller risk ratios not clinically relevant.

The location of the aneurysm was divided into (1) anterior communicating artery (Acom) and the anterior cerebral artery (ACA); (2) middle cerebral artery (MCA); (3) internal carotid artery (ICA), including the posterior communicating artery; and (4) posterior circulation. We categorized the shape of the aneurysms into spherical, oblong, oval and multilobed as described previously based on the maximal length and width of they aneurysm [3]. Maximal length is the largest distance measured between two points on the aneurysm which can be connected by a straight line. Maximal width is defined as the length of the longest perpendicular straight line on the line representing the maximal length. A spherical aneurysm is defined as a width of $81-100 \%$ of its maximal length, an oval aneurysm as a width of $61-80 \%$ of its maximal length and an oblong aneurysm as a width of $60 \%$ or less of the maximal length. Direction of blood flow is classified into three groups based on two angles measured at the point of the aneurysm, whereby " $\mathrm{A}$ " is defined as the angle made by the feeding vessel with the aneurysm and " $B$ " the angle made by the feeding vessel with the main branching vessel [3]. Blood flow is defined as curved when $\mathrm{A}$ is smaller than B. Thus, at the point of the aneurysm, a greater portion of the blood flows into the main branching vessel than into the aneurysm. When $\mathrm{A}$ is greater than $\mathrm{B}$, and, therefore, more blood flows into the aneurysm than into the main branching vessel, blood flow is defined as straight. Finally, when the difference between $\mathrm{A}$ and $\mathrm{B}$ is less than five degrees, the blood flows are considered equivalent.

We calculated relative risks (RRs) with corresponding $95 \%$ confidence intervals (95\% CIs) for the clinical and the aneurysmal characteristic. Regarding to location of the aneurysm and the direction of blood flow, we compared each location and direction separately with the other locations and directions combined as reference respectively. For shape, we compared spherical with nonspherical and calculated RRs with 95\%CIs for oblong, oval and multilobed with spherical as reference in addition.

\section{Results}

The 310 included patients had a mean age of 57.9 years (range 22-88). Of these patients, 75 (24\%) had an ICH. The mean age of the group that developed an ICH was 56.8 years (SD 12.8), and of the group without $\mathrm{ICH}$ it was 58.3 years (SD 13.6). The clinical and aneurysm characteristics and their risks for presence of an ICH are shown in Table 1. RRs for ICH of the clinical factors studied varied from 0.5 (95\% CI $0.2-1.3)$ for positive family history to 1.2 (95\%CI $0.7-1.8$ ) for males and were statistically not significant. Of all aneurysmal characteristics analysed, only the location of the aneurysm at the MCA (RR $1.895 \% \mathrm{CI}$ 1.2-2.5) was statistically significantly associated with the presence of an $\mathrm{ICH}$.

\section{Discussion}

The location of the aneurysm is a risk factor for presence of an $\mathrm{ICH}$ in patients with aneurysmal SAH: aneurysms originating from the MCA are associated with a higher risk than aneurysms at other locations. Other aneurysmal and clinical characteristics we studied were not associated with the presence of an ICH.

The absence of clinical factors as determinants for $\mathrm{ICH}$ from aneurysmal rupture is in line with previous studies. A study of 512 patients with SAH from Japan found no significant relationship between age and gender with ICH [4]. In another prospective series of 1,076 patients, again, no differences were found for age, gender or hypertension between the group with or without ICH [2]. One study did find a difference in age between patients with (59 years) and those without (52 years), but this study was restricted to patients with MCA aneurysms [5]. Since we had not pre- 
Table 1 The risk of developing an ICH for all characteristics studied

\begin{tabular}{|c|c|c|c|}
\hline & $\begin{array}{l}\text { No. of patients with } \\
\text { ICH }(\%)\end{array}$ & $\begin{array}{l}\text { No. of patients without } \\
\text { ICH }(\%)\end{array}$ & $\begin{array}{l}\text { Relative risk } \\
(95 \% \mathrm{CI})\end{array}$ \\
\hline Clinical characteristics $(N=310)$ & $N=75$ & $N=235$ & \\
\hline \multicolumn{4}{|l|}{ Gender } \\
\hline Male & $19(25.3 \%)$ & $51(21.7 \%)$ & \multirow[t]{2}{*}{$1.2(0.7-1.8)$} \\
\hline Female & $56(74.7 \%)$ & $184(78.3 \%)$ & \\
\hline \multicolumn{4}{|l|}{ Age } \\
\hline$\geq 55$ year & $41(54.7 \%)$ & $131(55.7 \%)$ & \multirow[t]{2}{*}{$1.0(0.7-1.4)$} \\
\hline$<55$ year & $34(45.3 \%)$ & $104(44.3 \%)$ & \\
\hline \multicolumn{4}{|l|}{ Smoking } \\
\hline Yes & $28(37.3 \%)$ & $104(44.3 \%)$ & \multirow[t]{3}{*}{$1.0(0.6-1.6)$} \\
\hline No & $23(30.7 \%)$ & $84(35.7 \%)$ & \\
\hline Unknown & $24(32.0 \%)$ & $47(20.0 \%)$ & \\
\hline \multicolumn{4}{|l|}{ Hypertension } \\
\hline Yes & $40(53.3 \%)$ & $145(61.7 \%)$ & \multirow[t]{3}{*}{$0.9(0.5-1.5)$} \\
\hline No & $16(21.3 \%)$ & $51(21.7 \%)$ & \\
\hline Unknown & $19(25.3 \%)$ & $39(16.6 \%)$ & \\
\hline \multicolumn{4}{|l|}{ History of SAH } \\
\hline Yes & $1(1.3 \%)$ & $6(2.6 \%)$ & \multirow[t]{3}{*}{$0.6(0.1-3.8)$ * } \\
\hline No & $70(93.3 \%)$ & $227(96.6 \%)$ & \\
\hline Unknown & $4(1.3 \%)$ & $2(0.9 \%)$ & \\
\hline \multicolumn{4}{|l|}{ Family history of SAH } \\
\hline Yes & $4(5.3 \%)$ & $33(14.0 \%)$ & \multirow[t]{3}{*}{$0.5(0.2-1.3) *$} \\
\hline No & $35(46.7 \%)$ & $130(55.3 \%)$ & \\
\hline Unknown & $36(48 \%)$ & $72(30.6 \%)$ & \\
\hline Aneurysm characteristics $(N=100)$ & $N=50$ & $N=50$ & \\
\hline \multicolumn{4}{|l|}{ Location } \\
\hline Acom and ACA & $21(42.0 \%)$ & $19(38.0 \%)$ & $1.1(0.7-1.6)$ \\
\hline MCA & $21(42.0 \%)$ & $8(16.0 \%)$ & $1.8(1.2-2.5)$ \\
\hline ICA & $6(12.0 \%)$ & $15(30.0 \%)$ & $0.5(0.3-1.0)$ \\
\hline Posterior circulation & $2(4.0 \%)$ & $8(16.0 \%)$ & $0.4(0.1-1.3)$ \\
\hline \multicolumn{4}{|l|}{ Shape } \\
\hline Spherical & $9(18.0 \%)$ & $8(16.0 \%)$ & \\
\hline Non-spherical & & & $0.9(0.6-1.5)$ \\
\hline Oblong & $14(28.0 \%)$ & $10(20.0 \%)$ & $1.1(0.6-1.9)$ \\
\hline Oval & $17(34.0 \%)$ & $13(26.0 \%)$ & $1.1(0.6-1.9)$ \\
\hline Multilobed & $10(20.0 \%)$ & $19(38.0 \%)$ & $0.7(0.3-1.3)$ \\
\hline \multicolumn{4}{|l|}{ Blood flow } \\
\hline Straight & $26(52.0 \%)$ & $22(44.0 \%)$ & $1.2(0.8-1.7)$ \\
\hline Curved & $15(30.0 \%)$ & $17(34.0 \%)$ & $0.9(0.6-1.4)$ \\
\hline Equivalent & $9(18.0 \%)$ & $11(22.0 \%)$ & $0.9(0.5-1.5)$ \\
\hline
\end{tabular}

* Relative risk calculated based on less than 310 patients because data were not available for all

specified this analysis beforehand, we have not performed the subgroup analyses.

Our finding that MCA aneurysms have a higher risk for ICH than aneurysms at other locations has been previously suggested [2, 6]. Most other aneurysmal characteristics studied had no or only little influence on the risk of $\mathrm{ICH}$, with point estimates of the RR close to one. Because small increased or decreased RRs have no clinical relevance in deciding to treat an unruptured aneurysm or not, larger studies will not be embarked upon with enthusiasm.

We did not routinely use rotational digital subtraction angiography in our study population because in clinical practice treatment decisions and actual treatment are usually done on CT- or conventional angiography in our 
centre. We could, therefore, not reliably assess the presence of blebs on aneurysms, and did not include this characteristic in our set of determinants. The lack of routinely catheter angiography also precluded sophisticated flow measurements within the aneurysms. Another potential limitation of our study is the selection of patients for the assessment of radiological factors. We did not randomly retrieve patients, but selected patients on date of admission, starting with the last admitted patients. We have chosen this method because of its efficiency, as many older CT-angiograms were not easy to access. Since the retrieval of this subset of patients was done retrospectively and independent from clinical or other radiological factors, we believe this type of retrieval has not introduced any bias. The proportion of patients with ICH from a ruptured aneurysm in our studies is comparable to proportions in other studies, which supports the external validity of our study $[7,8]$.

The location of the aneurysm is a determinant of risk of ICH. Most of the other clinical and radiological characteristics we studied, are easily examined in daily practice, but have no predictive power for the presence of ICH. They can, therefore, not be used in clinical practice in the risk balance for treatment of unruptured aneurysms. Other aneurysmal characteristics, such as pulsatility and intraluminal flow patterns may be related to risk of ICH in case of ruptures, but for assessment of these characteristics, more sophisticated tools are needed than available in daily practice.

Acknowledgments We would like to thank Heleen Lans, Nicolien K. de Rooij and Birgitta K. Velthuis, for their help in reviewing the CT-angiograms. The authors have no competing interests to declare. No funding was obtained for this study.
Open Access This article is distributed under the terms of the Creative Commons Attribution Noncommercial License which permits any noncommercial use, distribution, and reproduction in any medium, provided the original author(s) and source are credited.

\section{References}

1. Van Gijn, Kerr RS, Rinkel GJ (2007) Subarachnoid haemorrhage. Lancet 369:306-318

2. Hauerberg J, Eskesen V, Rosenorn J (1994) The prognostic significance of intracerebral haematoma as shown on CT scanning after aneurysmal subarachnoid haemorrhage. $\mathrm{Br} \mathrm{J}$ Neurosurg 8:333-339

3. de Rooij NK, Velthuis BK, Algra A, Rinkel GJ (2009) Configuration of the circle of Willis, direction of flow, and shape of the aneurysm as risk factors for rupture of intracranial aneurysms. J Neurol 256:45-50

4. Tokuda $\mathrm{Y}$, Inagawa $\mathrm{T}$, Katoh $\mathrm{Y}$, Kumano $\mathrm{K}$, Ohbayashi N, Yoshioka H (1995) Intracerebral hematoma in patients with ruptured cerebral aneurysms. Surg Neurol 43:272-277

5. Yoshimoto Y, Wakai S, Satoh A, Hirose Y (1999) Intraparenchymal and intrasylvian haematomas secondary to ruptured middle cerebral artery aneurysms: prognostic factors and therapeutic considerations. Br J Neurosurg 13:18-24

6. Nakagawa T, Suga S, Mayanagi K, Akaji K, Inamasu J, Kawase T (2005) Predicting the overall management outcome in patients with a subarachnoid hemorrhage accompanied by a massive intracerebral or full-packed intraventricular hemorrhage: a 15-year retrospective study. Surg Neurol 63:329-334

7. Berlit P, Buhler B, Tornow K (1988) CT findings in subarachnoidal haemorrhage (SAH). A retrospective study of 138 patients. Neurochirurgia (Stuttg) 31:123-127

8. Rosenorn J, Eskesen V, Schmidt K, Espersen JO, Haase J, Harmsen A, Hein O, Knudsen V, Midholm S, Marcussen E (1987) Clinical findings and prognosis in 1,076 patients with ruptured intracranial saccular aneurysm. A prospective consecutive study. Ugeskr Laeger 149:2908-2911 